\title{
Service Specification Modelling for Procurement Decision Making
}

\author{
Sharfuddin Lisan \\ Supply Chain Department, Bangladesh Institute of Human Resource Management (BIHRM), Dhaka, Bangladesh \\ Email address: \\ lisanbd@ymail.com

\section{To cite this article:} \\ Sharfuddin Lisan. Service Specification Modelling for Procurement Decision Making. International Journal of Business and Economics \\ Research. Vol. 7, No. 2, 2018, pp. 31-41. doi: 10.11648/j.ijber.20180702.12
}

Received: May 5, 2018; Accepted: May 21, 2018; Published: June 13, 2018

\begin{abstract}
Service is defined as economic activities that produce time, place, form, and/or psychological utility. It is intangible, perishable, created and consumed simultaneously [1]. Every product has some form of service [2]. Thus Service specification is necessary to get desired product and service from any purchase. In literature, there are different dimensions of services. In this article, services are classified into three categories: importance of service, expected quality from service and willingness to spend to get a service. Considering these areas, a metrics is developed that could help to identify expected service in terms of cost, importance \& quality. Combined with internal and external measures of service, the matrix will also help to understand the features of potential supplier \& service, take actionable strategy to get desired services and take effective service product purchase decision.
\end{abstract}

Keywords: Service Specification, Service Features, Service Positioning Model, Procurement of Services

\section{Introduction}

Services are critical for our business \& daily needs. In fact most of our needs comes in the form of Service. Even our Material needs are evaluated in the form of derived service [3]. Therefore, Service purchasing is crucial for business as It is a strategic commercial function that contributes to the competitive standing of any company $[4,5]$. However, to purchase service at the very outset there is need for specifying services. But every time we try to determine our required specification for service, we find vagueness to the same. So there is need for some short of procedure or techniques of service specification.

\subsection{Background and Context}

In daily life we need numerous variations of products to satisfy our need. We need food as well as the service to reach that to us. We require Transportation means to visit, at the same time the service to be in our desired destination. Based on consumers need, the business world identified there are only two shorts of products are needed to compensate people needs. Physical/Material products-those are tangible and Service products are intangible. The Physical products are easy to identify as these are consciously tangible. The consumers can effortlessly identify and demand its features, specifications, dimensions, outlook, performance, durability, reliability, productivity \& finally form a rigorous evaluation. On the other hand identifying specifications of service products are exactly opposite to materials.

As intangible product, Services pretty hard to specify \& set perfect method for evaluation. These are heterogeneous in nature [2]. Physical products may be grouped in terms their dimensions but the services differ despite the responsibilities are same depending on individual, environment and situations. Another feature is that Services are produced and consumed at the same time [2]. As service cannot be stored as these are perishable too.

There is also Customer service in support of company's core products. It could be on-site (as when retails employees help to find desired item or answer to a question) or off-site service via internet/Phone.

There is another kind called 'Derived service'. In Journal of Marketing, Steve Vargo and Bob Lusch [3] argue that, all products are justified on the basis of services they provide. Value derived from physical goods is actually the service provided by the product, not the product itself. Like Television provide video service or Cell phone provide 
communication and information service etc.

Service products are important determinant for GDP. More than $50 \%$ of GDP comes from Service Products in many countries Canada $72 \%$ in 2011-12 [6], India 58\% in 2013-14. [7], Bangladesh 57\% in 2015-16 [8]. In Australia $68.8 \%$ of GDP is earned from service sectors (2012) [6]. In USA, different services occupied most of the GDP's calculation. Government services-13\%, Information \& Entertainmnet-11\%, Professional \& Business Services-11\%, Education \& health services-8\%, Transport \& Warehouse$5 \%$, Wholesale \& Retail trade-13\%, Finance Insurance real eatate-20\% (2003) [2]. In 2012 Bangladesh's GDP's 54.1\% way occupied by service sectors. Where agriculture contributed $17.3 \%$ \& industry $28.6 \%$. In 2008, 25\% Labor force was employed in service sector, where agriculture $45 \%$ \& industry: $30 \%$ [8].

However there are different shorts of Services For example, Finance, Insurance, Real Estate, Wholesale, Retail Trade, Transport, Warehousing, Utility, Education \& Health, Professional \& Business services. Others like Printing, Cleaning, Food service, Telecommunication, Advertisement, courier etc.

Now we comprehend the importance and contribution of services in the economy. So if we talk about service product's purchase, it should be done carefully that we can satisfy our expectation. As it is hard to pinpoint our need.

There is a model called "Supply Positioning model" developed by Peter Kraljic. It mainly helps to decide on Physical product purchase decision. Where he suggested four kinds of products Routine item, Leverage item, Bottleneck item \& critical item [9]. Sometime it helps to service products too. But as the service is complicated product, there is need for designing individual model for the same containing only service related features, which will help to pinpoint service product purchase decision. So only the Service related model is required.

\subsection{Objective}

The objective of the paper is to determine the exact service and its features needed by a purchaser. For this we are assuming service is the determinant from the combination of service quality, service cost and importance of the service to the customer.

\subsection{Research Question}

The questions of this research is (i) what are the recognized service features expected by customers? (ii) Are combination of service quality, service cost and importance of the service could determine a single service need by customer? (iii) Can we form a single matrix by including expected services required by purchaser?

\subsection{Implications}

The outcome of the study will help to identify the service expectation form customers and devise strategy around that.

\subsection{Rational of the Study}

As Service products are hard to specify. The products purchased very often dissatisfies the end customer. So a mechanism should be developed to pin point the expected service level so that analyzing the same a purchaser could determine the specific service \& select the supplier who can satisfy his/her needs in full.

This study will help any individual as well as organization to take decisions on Service product specification \& acquisition of the same to get expected service \& utilize the invested capital fully.

\section{Literature Review}

Purchasing decisions considers internal requirements, External relationship with supplier \& Impact on final product or quality $[10,51]$. At the beginning, researchers of the procurement arena tried to define different magnitudes of service quality. Based on a survey, Cavinato [11] proposed some features of service quality performance. These include fast delivery, reliable service and product, and facts about possible delivery and quality difficulties. Rossler and Hirsz [12] worked on the internal service quality. They discovered that collaboration with internal customers improved the opinion that procurement was responsive to the needs, where technical awareness was important to satisfactory performance. Young and Varble [13] worked with 22 areas of the SERVQUAL [15] and other standards identified by purchasers [19] into their survey and recognized reliability and responsiveness as the most significant dimensions of performance for procurement and satisfy internal customers.

Zeithaml et al. [17] found obstacles to deliver improved service quality to external customers based on a 'Gap Model'. This model works with the difference between expectations and perceptions of service quality. Considering dimensions of service quality, tangibles, reliability, responsiveness, empathy, and assurance, they developed SERVQUAL questionnaire- a multiple-criteria scale [50]. Their 1991 study indicates the prerequisite for external customers are coordination and - consistent communication.

Young and Varble [13], also worked on the literature on service quality measurement. This area of research has been established based on the work of Parasuraman [14] [15] and Young and Varble [13]. Reynoso and Moore [20] said that, SERVQUAL model established by Parasuraman et al. [16] could be convertible to any institution's internal setting based on interviews and written surveys. In SERVQUAL, 10 dimensions of service quality emerged using factor analysis and were closely aligned to Parasuraman et al.'s [16, 21] measurements of external service quality [50]. These are composed of overlapping dimensions of service delivery quality: tangibles, reliability, responsiveness, communication, credibility, security, competence, courtesy, understanding/knowing the customer, and accessibility.

However, Lewis and Gabrielsen [22] and Lewis and Koula [23] also agreed that ensuring internal quality effectively was 
important to external service quality, although they concluded that the SERVQUAL instrument was not without drawbacks. Cronin and Taylor [24, 25] and Teas [26] disagreed with Parasuraman et al.'s $[15,16]$ and Zeithaml et al.'s [21] and commented that performance-based methods were better for assessing service quality.

Finn et al. [27], recognized the argument against Parasuraman et al.'s SERVQUAL methods, and developed a tool to measure quality delivered by one organizational unit to another. Finn et al. [27] acknowledged internal service as "a two-way exchange between different wings of organization of a firm, there, the provider of service is charged with answering to the requirements of internal customer (p. 37)". They observed at service requirements of procurements internal customers through individual and group questionnaires based interviews, and indicated that internal customers had several expectations, including flexibility, communication, and ability to manage suppliers. On the other hand, Kaplan and Norton [28, 29] argued that procurement managers should consider performance from a financial and operational viewpoint. Using a "balanced scorecard" by specifying expected internal measures and internal service including different dimensions of time, quality, service, performance and cost.

Study on relationship between internal and external service quality was found nominal. A study on organizational behavior found that an affirmative relationship is seen between service oriented HR practices and consumer views of service quality [30]. However, Flynn et al.'s [31] resulted a bit different approach. They measured the actual output of products in a manufacturing facility as the percent of items that passed quality inspection without rework. External performance is explained as a measure of the plant's program and contribution to the facility's distinctive competencies. Using regression analysis, process management identified as related to internal quality performance, while it was found not that much significant to external quality performance. The weakness of the study was that, a single scale was used to determine internal quality performance. In summary, the SERVQUAL instrument is a popular method to identify service quality, in many ways, it was found not fully reliable or valid means to measure service quality. In practice, not always it was easy to translate the service specification for the internal organizational setting of purchasing. Others, including Cronin and Taylor [24, 25], Kaplan and Norton [28, 29] Teas [26] argued that performance was significant than perceptions and expectations.

Research on internal service quality is objectively rich regarding their relationship to service quality provided to external clients, compared to that, little research was found centered on external performance measurement issues, and/or bridge between internal or external service quality and service quality received by the organization. Moreover, procurement's role in the organization of quality from external suppliers to internal customers and external customers, has also not been recognized properly.

Quality of service is difficult to measure for the nature of service itself. Berry et al. [32] and Parasuraman et al. [14] $[16,17]$ stated that customers compare service expectations and received service and measure the quality thereafter. As employees are engaged with service delivery, employee performance play an important role on customer perceptions of service quality.

Harvey [33] discussed that service quality works with two dimensions: actual results and the process to accomplish results. Actual result of quality takes place when service suppliers are able to supply customers consistently with reliability and of course with no "negative surprises", [33]. Process quality happens when suppliers satisfy customers with technical and perceptual aspects.

Technical quality is achieved when the process ensures specified ideal measures, while Harvey included Parasuraman et al.'s four dimensions of service quality. These are empathy, responsiveness, assurance, and tangibles. According to Peters [34], ensuring effective cross-functional communication and team work, organizations can accomplish technical quality, therefore, perceptual service is important, and it could be structured at the strategic stage.

\section{Models for Purchase Specification}

\subsection{Kraljic's Supply Positing Model}

Peter Kraljic developed a supply positioning model to classify and analyze purchasing portfolio of any purchase [9].

In a matrix the poisoning model is depicted and distributed into four categories. These are sourcing management, materials management, purchasing Management, supply management [9].

Materials management is regarded as leverage items, such as tires and spare tires in car to keep inventory for safekeeping. For these products, purchase should keep more than one supplier to ensure product flow. Engaging many suppliers benefit the organization to reduced price. [9].

Supply management indicates critical items, for example, Engine of a car as it bears the major cost in the whole body of car. Decision making for this product is taken at the top level. According to Karljic [9], business should aim for extended-term contract with suppliers. [9].

Purchasing Management is for non-critical items. Stationary and office supply for example. The suppliers of this product tend to be limited terms. [9].

Sourcing management directs to the low price but high risky bottleneck items. For example gas or machine oil of a car. A mix of centralized-decentralized strategy is needed for this product. Purchaser should look for long term responsive supplier for this type of product [9]. 


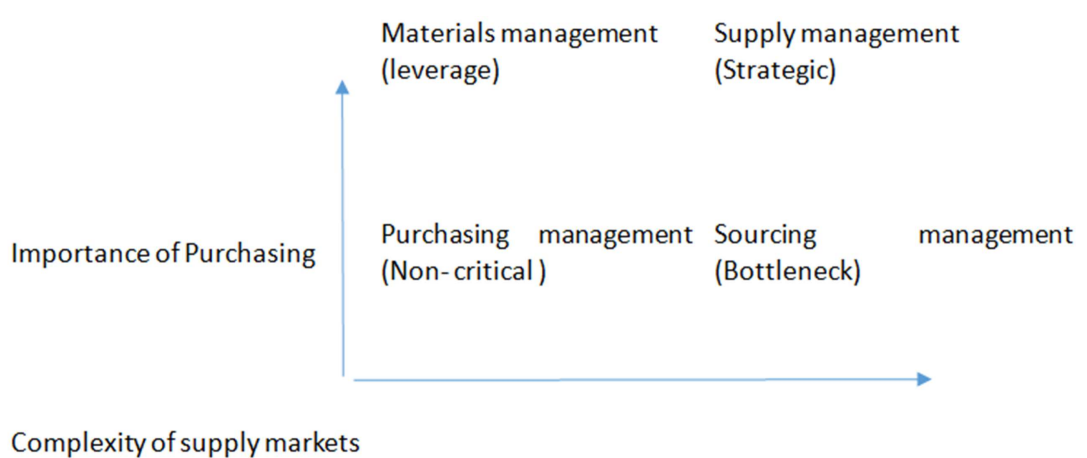

Figure 1. Kraljic's Supply Positing model [9].

There are many interpretation of Karljic Matrix. One of these was mentioned by Lilliecreutz \& Ydreskog [35]. They reproached the terms and order karljic used, but the core idea remained same.

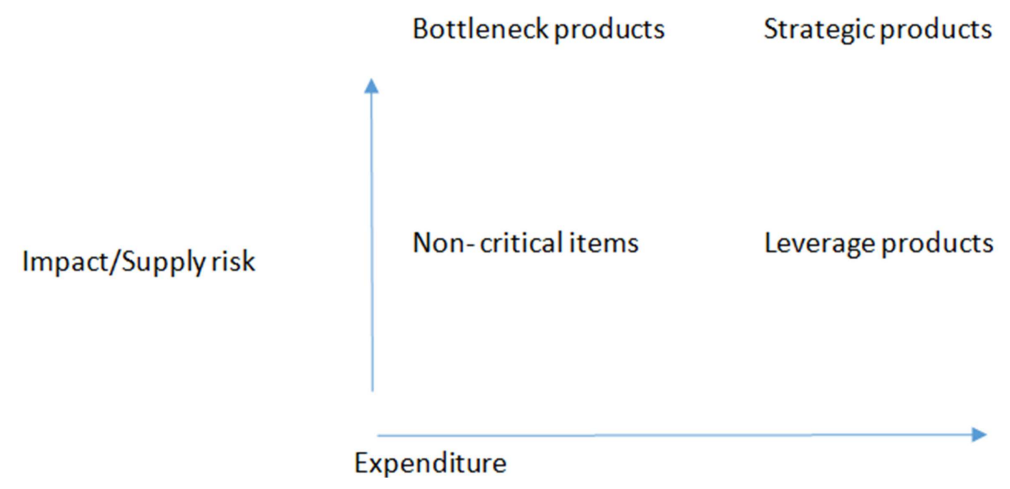

Figure 2. Supply Positing model by Lilliecreutz and Ydreskog [35].

\subsection{Supplier Segmentation}

Håkansson \& Persson, [36] devised a model for supplier segmentation based on three different interdependencies identified by Thompsen [37]. These are called serial, pooled, and reciprocal interdependencies.

Pooled -Here relationship between two players are indirectly dependent as they are both are related to a $3^{\text {rd }}$ party and sharing the same channel and resource. Thus it can lead to economies of scale and/or economies of scope.

Serial - This is combination of serial of activities.
Therefore the outcome of one activity is the input for the subsequent activity.

Reciprocal - This interdependence includes exchange of input-output between two players. Innovation in economics and agility could be achieved if the players can work together.

Håkansson \& Persson, [36] proposed supplier segmentation model could b used to identify basic supplier relationships and what areas management should focus on. These are showed in Table:

\begin{tabular}{|l|l|l|l|}
\hline Type of economy & Interdependency & Management focus \\
\hline StandardisationEconomies of scale similarity and scope specialization & Pooled interdependencies & Mediating (connecting to others) relationship & \\
\hline Economies of integration & Serial interdependencies & Coordination and adaptation & Linked (stream - lined)relationship \\
\hline Economies of innovation and agility & Reciprocal interdependencies & Confrontationand learning \\
\hline
\end{tabular}

Figure 3. Supplier Segmentation model by Håkansson and Persson [36].

\subsection{Mutual Dependence Based Purchasing Portfolio}

Gelderman's, [38] Buyer- Supplier Dependence model describes a matrix that uses crosswise axis. There are two axis: one is concerning power, another is regarding importance of product. The axis split the matrix into buyer dominated area and supplier dominated area. In this model, Gelderman, [38, 47] followed the Kraljic matrix. Rotate it using axes to focus on power and importance in the matrix. 


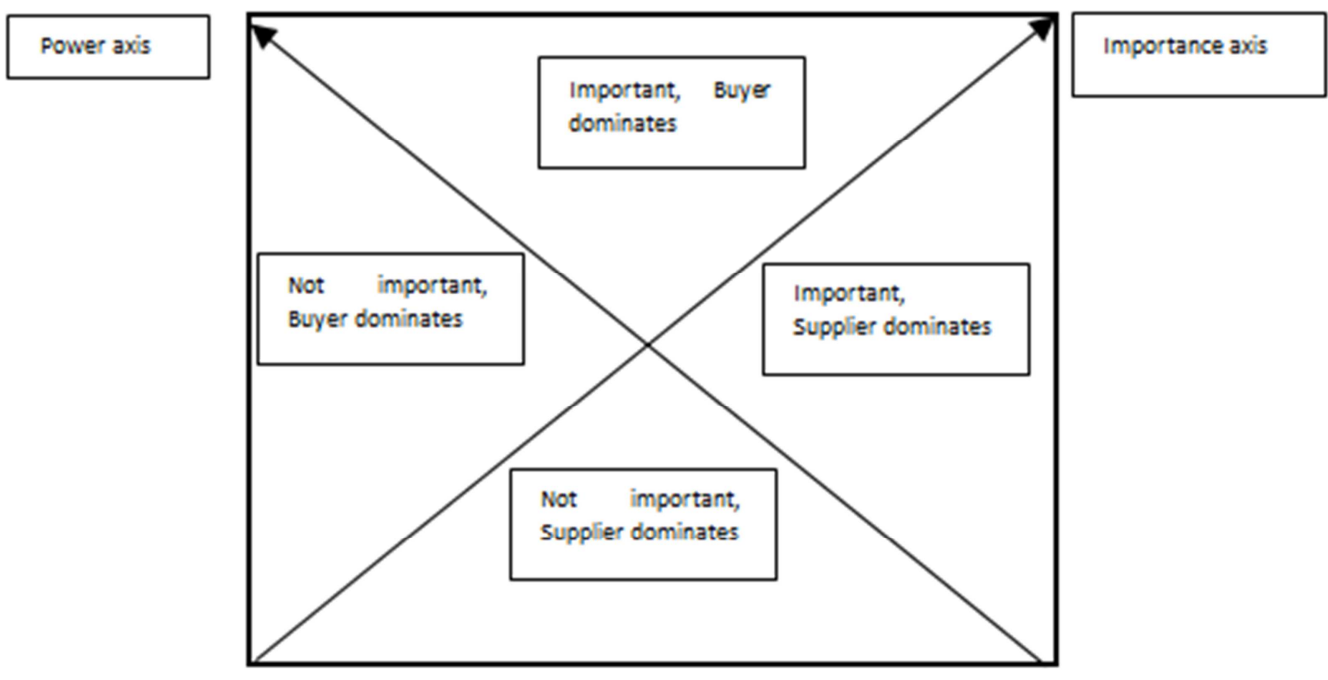

Figure 4. Mutual dependence based purchasing portfolio by Gelderman [38].

\subsection{Purchasing Strategies on Supply Situations}

Van Stekelenborg \& Kronelius, [39] proposed a purchasing model to characterize supply situations. The authors suggest that purchasing constitutes of the suppliers-the resource, and also identifying the demand side. In other words- production control. The authors define purchasing is a function that aims at satisfying the market demand, while employing the right sources from the supply market." [39]
Internal market demand and the need for external supply market is classified as "high" to "low". From this concept, a matrix is devised. The internal market demand placed on the vertical axis and the need for external supply market control is on the horizontal axis. This points to four types of situations for supply. Plain supply solution, externally problematic supply solution, internally problematic supply solution and complicated supply solution [39].

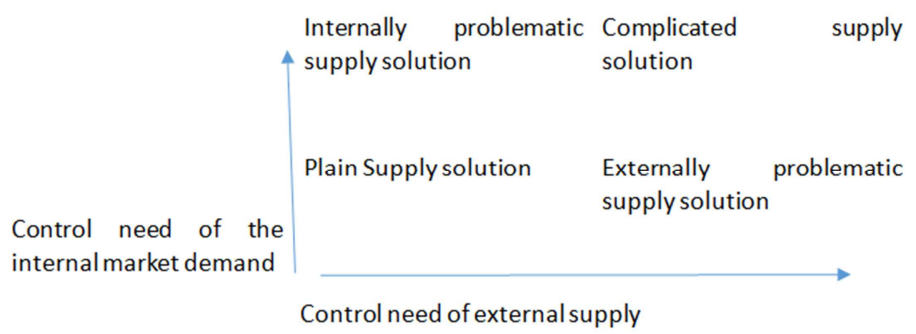

Figure 5. Purchasing strategies on supply situations by Stekelenborg and Kornelius [39]

\subsection{Managing Supplier Segmentation Portfolio Models and Relationships}

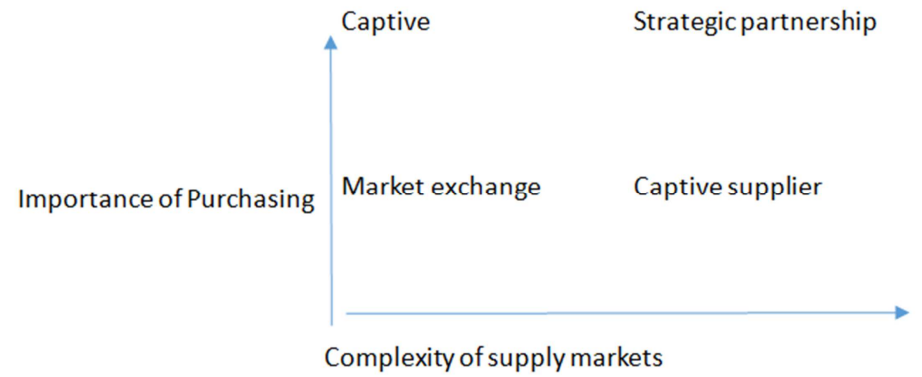

Figure 6. Supplier segmentation portfolio models and relationships by Olsen and Ellram, [40].

Olsen, et al., [40] proposed a model that deals with supplier relationships, in terms of importance of purchasing and complexity of supply markets

Further, Olsen \& Ellram [40] suggest, supplier buyer relationship should be such kind where it will add value to improve the understanding of the additional dimensions that needs to be considered in case of supplier segmentation and its interactions. Here, different modes of relationship is used to identify market exchange, captive, strategic partnership or captive supplier relation to establish and identify a common interest for supplier and buyer. 


\section{Service Positioning Model: Background}

When we think of purchasing a service, First thing comes in our mind, how important the service is to us. Not always service is important to us to high degree. (i) Sometimes we look for instant service. For example, when we line up to buy bus ticket, the period of interaction is not that long. Just payment and ticket exchange. If we stand in line for long, we expect it line would have been shorter, or the ticket should be issued faster. If there is only one person in that line, we expect at least financial transaction would have been faster. However, in daily life, compared to other tasks, this ticket service is not that important to us if we can manage to line up for bus ticket on time as we become assured, we will get the ticket anyway. We can call that 'Developing service', as we currently we do not need that much fast delivery but hope it will be better next time. (ii) But in case, we are on the road. On the way to the bus station, or we are in the office, we do not have time to book a bus or air ticket. At that time we expect to have the responsiveness from the ticket supplier that they will book our ticket instantly. For example a responsive travel agency or instant online booking system could facilitate the need of customer. This level we can call 'Responsive service' (iii) However, there may other cases, where we may need of instant need of riding a bus or plane. We did not have time to book in advance or call our travel agencies to check online for current ticket price. Therefore, the importance of ticket becomes so high. In that case, the need for ticket buying service becomes 'Core service' for us.

\begin{tabular}{|l|l|l|}
\hline \hline $\begin{array}{l}\text { Developing/ } \\
\text { Recovery } \\
\text { Service }\end{array}$ & $\begin{array}{l}\text { Responsive } \\
\text { Service }\end{array}$ & $\begin{array}{c}\text { Core } \\
\text { Service }\end{array}$ \\
\hline
\end{tabular}

Figure 7. Importance of Service continuum.

Alongside importance, we think of service cost we are ready to spend. Are we always keep our expense tight or spend a lot in terms of service purchasing? It depends on the situation. For example, (i) If we wish to buy foods compared we are agreed to, we expect that kind of service from the food derived service. For example, if we are like to spend less, we know, the service will be less. As for example we eat bread with Jello, the derived service from the food will be less in case of apatite fulfillment. This stage we are calling 'Temporary service'. (ii) In case of full meal, we may need to increase the budget. To fulfill the hunger. This stage we call 'Functional service' from the food. (iii) If our budget of food is higher than that, naturally we expected better service from the food. This stage we are calling 'Adaptable of Customized service'. As we want customized food made as per our increased budget.

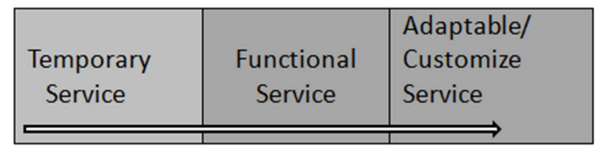

Figure 8. Cost of service continuum.
Another criteria we assume, is quality of service. After importance and cost consideration, we cannot skip the need of considering quality. Not always we look for highest quality of service. (i) For example, if we are injured a bit, just a scratch on the hand, we need immediate service of stopping the pain or spilling of blood. This is we are calling 'Temporary service', as we know the service will be is immediate and temporary. Thus we do not expect that much longevity- quality from this.

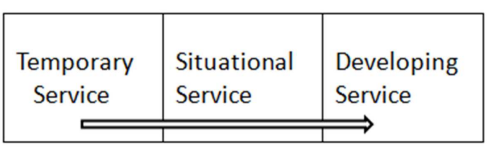

Figure 9. Quality of service continuum.

(ii) If our injury is severe, we need better service rather than just stopping the blood. We may need to go for immediate surgery, or professional attention if the patients had or leg is broken. Here we are expecting better service quality as we need to fix severe health issue. We could call this level as 'Situational service' as we need higher quality service based on situation and contingency. (iii) Moreover, if the injury needs long term attention, our expectation from the service gets higher as we assume, health professionals are getting more time than 'Situational service' and usually long time health services needs recurring fees- the service quality supposed to be better than previous ones. This stage we can call 'Developing service'.

In median of all these service features there could be 'Service Assurance'. This is a level where a purchaser could expect a desired service level from any product. If the expected service level is more than 'Assurance service', the next level we could call 'Reliable Service'.

These phenomena may fluctuate. Sometimes our need is high but we are not ready to pay the same way, as there may be alternative services to the same problem. Same way, we want to pay high but the need is minimum to the business, as we may need instant service or the service may not be available in the future. Situations may fall between two extremes.

Our metrics is based on these important variables and combinations of- Expected service quality, Willingness to pay the cost of received service, Importance of service.

On the vertical line we consider the quality of service. The horizontal lines are divided in two parts- The cost of service is placed on the base/lower horizontal line and the importance of service is placed on upper horizontal line. As price is the base of service purchase, it is placed as base and cost expenditure is related to importance of service, it is placed on the opposite side. All the variables are given specific degrees 1-9 based on the requirements we need.

The whole metrics is divided into 9 different service expectations. As we increase the degree of expectation from the quality increases. Likert scale [41, 42] is used to determine the degree of choice. 


\subsection{The Service Positioning Model}

\begin{tabular}{|c|c|c|c|c|}
\hline \multicolumn{5}{|c|}{ Service Positioning Model } \\
\hline & & \multicolumn{3}{|c|}{ Importance of Service } \\
\hline \multirow{6}{*}{$\begin{array}{l}\text { Expected } \\
\text { Service } \\
\text { Quality }\end{array}$} & \multirow{6}{*}{$\begin{array}{l}\sigma \\
\infty \\
\sim \\
0 \\
n \\
+ \\
m \\
N \\
-1\end{array}$} & 12 & 45 & 89 \\
\hline & & Developing/ & $\begin{array}{l}\text { Responsive } \\
\text { Service }\end{array}$ & $\begin{array}{l}\text { Core } \\
\text { Service }\end{array}$ \\
\hline & & $\begin{array}{l}\text { Situational } \\
\text { Service }\end{array}$ & $\begin{array}{c}\text { Service } \\
\text { Assurance }\end{array}$ & $\begin{array}{l}\text { Reliable } \\
\text { Service }\end{array}$ \\
\hline & & $\begin{array}{l}\text { Temporary } \\
\text { Service }\end{array}$ & $\begin{array}{l}\text { Functional } \\
\text { Service }\end{array}$ & $\begin{array}{l}\text { Adaptable/ } \\
\text { Customize } \\
\text { Service }\end{array}$ \\
\hline & & 123 & 56 & 8 \\
\hline & & \multicolumn{3}{|c|}{ Expected Cost of Service } \\
\hline
\end{tabular}

Figure 10. Service positioning model.

The 9 blocks have got 9 different characteristics. When Cost expenditure, importance, quality expectation ranks 1 or 2 , the metrics shows we want temporary service. Which indicate the service features we want. These may include

\subsection{Use of the Model}

First, we select importance of service. In this case, we use Likert scale [41, 42] Using the scale from 1-9, we need to identify our need. For example, we choose 2. On expected cost of service, we choose 4 . Now we can draw a line that starts from 2 of Importance of service and touches 4 of cost of service. Now, in expected cost of service line, we choose 4. Therefore it intersects to 'Situational service' area. We can look from below descriptions of different services, find out 'Situational service', understand the features and take strategy according to the category.

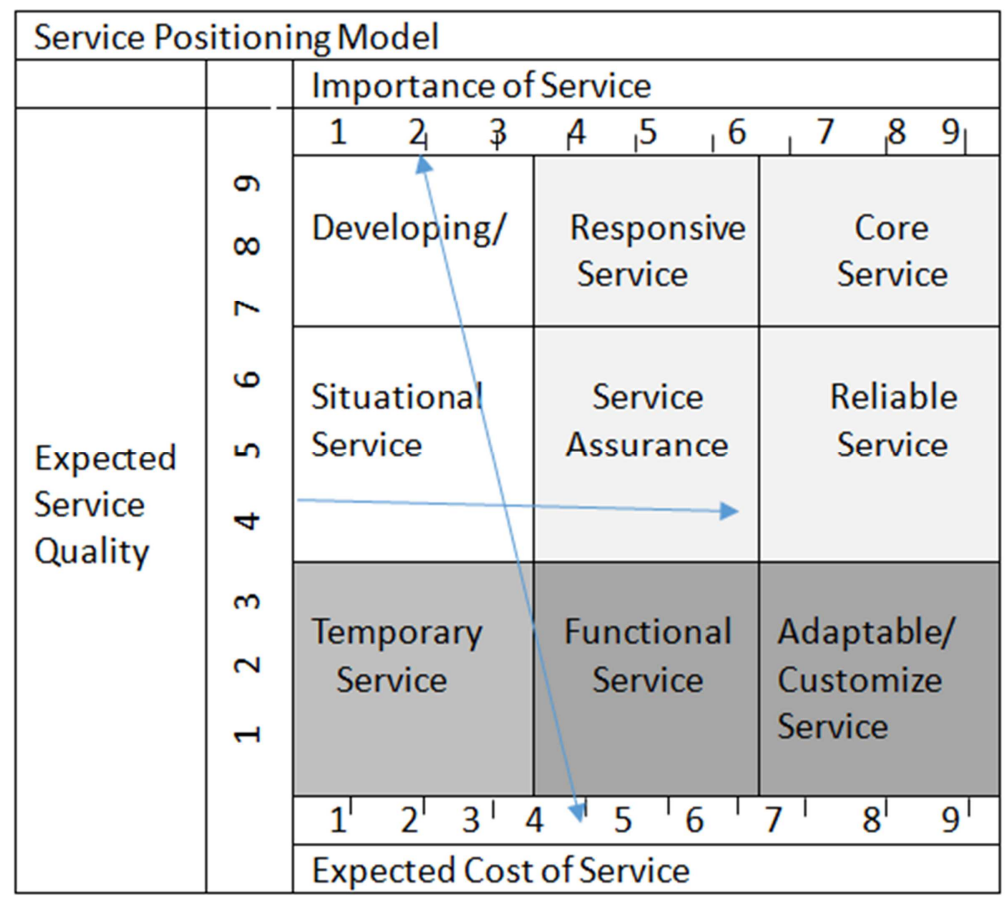

Figure 11. Use of Service positioning model. 


\subsection{Service Expectations from Service Supply Positioning Model}

\subsubsection{Reliable Service}

\section{(a) Features}

Generally Expected cost \& importance high, Quality expectation is medium. If this type of service is chosen, the purchaser is looking for following kinds of services.

Reliable service is the ability to perform the pledged service in dependable and accurate manner.

The supplier delivery on its promises. Assurances about delivery, Service Provision, Problem resolution \& Parsing.

The suppliers should core service attributes.

Absolutely positive -has to get there/service positioning. $[14-17,21,43,44]$

\section{(b) Strategy}

The supplier should have the capacity to rely on them and support mutually continuous improvement. There should be only one supplier thus relationship should partnership status in mind and long term contact should be placed. $[9,35]$

\subsubsection{Responsive Service}

\section{(a) Features}

Generally Expected cost \& importance is medium, Quality expectation is high.

If this type of service is chosen, the purchaser is looking for following kinds of services.

Willingness to help customers and provide prompt service.

Being willing to help.

It emphasize alternatives \& promptness in dealing with customer requests, questions, complains and problems.

Is communicated to customers by the length of time they have to wait for assistance, answers to questions attention to problems.

Captures the notion of flexibility and ability to customize the service to customs needs.

Company must view the process of service delivery and the handling of requests from the customer point of view.

Speed of promptness, Reflect company view of internal process requests.

To truly distinguish themselves on responsive, company need

Well-staffed customer service departments

Responsible front line people in all contact positions.

Perception distinguish when a customer wait to get through to a company by telephone, put on hold or complex voice mail or troubled website. [14-17, 21, 43, 44]

\section{(b) Strategy}

The supplier is critical to the business. So there should be only one supplier selected. Relationship should be cooperative/partnership. There should be long term contact. The supplier should be able to serve promptly, minimize the need for intervention, for individual service, have the capacity and will to serve. $[9,35,45]$.

\subsubsection{Assurance Service}

\section{(a) Features}

Generally Expected cost, importance \& Quality expectation all are medium.

If this type of service is chosen, the purchaser is looking for following kinds of services.

Employee knowledge \& ability to inspire trust \& confidence.

Assurance service is the ability of the firm and its employees to inspire trust \& confidence.

Particularly important for services that customers perceive high risk or for services of which they feel uncertain about their ability to evaluate outcomes.

For example banking insurance brokerage medical legal services.

Trust \& confidence may be established, such as security brokers, insurance agents, lawyers, counsellors, personal bankers. [14-17, 21, 43, 44]

\section{(b) Strategy}

Here the supply need may be little but it may extend in the future. Thus there should be one or two supplier. There should be good relation/ cooperation relation with supplier. Long term contact should be considered. The supplier should be able to serve with trust and confidence, should have capability for higher service in future \& they provide required list of service for future need. [9, 35, 45]

\subsubsection{Adaptability Service}

\section{(a) Features}

Johnson \& Nilsson [43] mentioned, adaptability or customization is more important than reliability in terms of more service centric products.

For this kind of services, Expected cost \& importance is high, Quality expectation is Low.

If this type of service is chosen, the purchaser is looking for following kinds of services.

It determines how adaptable the service delivery system is when the customer has special need or requests that place demand on the process.

Judge Service quality in terms of flexibility of the employees and the system.

Incident categorized by their theme all contain an implicit or explicit request for customization of the service to meet a need.

Customer see as special need may be routine from employees point of view. Customer thinks that something special is done for his/her individual needs. Service put effort to accommodate and adjust the system to meet their requirements.

Contact employees see their abilities to adapt the system as being a prominent source of customer satisfaction.

Like Hotel room, Emergency doctor service, Insurance support. [43]. 


\section{(b) Strategy}

Here the client should consider two/three supplier who will be able to serve to the customized need and able to serve best service possible within short notice. The relationship should need be minimum intervention. Spot/ short term contact should be considered. $[9,35,45]$

\subsubsection{Functional Service}

\section{(a) Features}

Generally Expected cost \& importance is medium, Quality expectation is Low.

If this type of service is chosen, the purchaser is looking for following kinds of services.

- No service failure, No special requests, customer finds service is frequent.

- Employee is Medicare / regular.

- Satisfying incidents in this group represent very pleasant surprises for the customer.

- Service serves its functionality, Normal Expected service is found. [46]

\section{(b) Strategy}

The functional supplier only serves the basic function we need. As the service is regular here should be two or more supplier. The relationship should be negligible/ arms-length. There could be spot purchase type of contact. The supplier should be able to perform least service that functional service require.

\subsection{6. 'Temporary'Service}

\section{(a) Features}

Generally Cost Low, Importance Low, Quality Low, Instant service.

If this type of service is chosen, the purchaser is looking for following kinds of services.

Contractual, Seasonal, Interim service, Short term.

For a certain period of time, Work based, Job based. Job completed, Contact withdrawn.

Purchaser expects instant service.

Like Waiter service. Comes, Serves and Goes. No relationship after that.

\section{(b) Strategy}

According to our model, in terms of temporary service, we should consider one supplier for single item frequent purchase need and many supplier for non-frequent individual services. The relationship is not that much concern as they are temporary and thus it should be minimum interference. The contract should be long term in terms of large supplier and spot contact for individual service. The supplier should able to supply as many as needed, minimize the need for intervention and for individual service after contract supplier assistance needed to get expected service. [9, 35, 45]

\subsubsection{Situational Service}

\section{(a) Features}

Generally Cost Low, Importance Low, Quality medium.
If this type of service is chosen, the purchaser is looking for following kinds of services.

When needed, best service expected. Doesn't need all time.

No time to specify specifications. So supplier should be able to assess the same, Reject rate low.

No maintenance interval.

Customer service, Doctor Service.

\section{(b) Strategy}

Requires 2 or more supplier for large purchase, one or two for individual purchase. The relationship status should ne arms-length. The contact type should be short term to get continued service with that period. The supplier should be able to supply instantly. [35]

\subsubsection{Developing Service}

\section{(a) Features}

Generally Cost importance is low, but quality expected is high.

If this type of service is chosen, the purchaser is looking for following kinds of services.

Service may not be needed now, But selecting supplier who will be able to do so \& continue to developed relationship.

Long term relationship.

High degree of cooperation is needed.

Recovery service like warranty/ Guaranty service.

\section{(b) Strategy}

Here the relationship status should be cooperative this one supplier should be selected carefully. There should be long term contact as the service need may extend in future. The supplier should be able to recover provide recovery service if any case, service fails. The purchase should provide guidance to supplier to serve better. [35, 45]

\subsubsection{Core Service}

\section{(a) Features}

Core Service: - Generally Cost importance \& quality expected is high.

If this type of service is chosen, the purchaser is looking for following kinds of services.

Combination of Responsive, Reliable, Assurance, Adaptable services.

Cost, importance \& quality high expected.

This is central concern of purchasers business.

Supplier with long term potential.

High degree of cooperation \& mutual development.

Fair \& reliable business partner.

Capable of all sorts of service. [9, 35, 45].

\section{(b) Strategy}

As this is the core service for business the supplier should be reliable, responsive and adaptable at the same time. The service provider should be able to quality of present and future services. There should be only one supplier. The relationship should have partnership status and there should 
be longest possible term contact. Mutual cooperation in every phase of action is required. [9, 35, 45]

\section{Implications of the Model}

This model could be used to specify and determine the exact service level requirement and devise procurement strategy according to that. Hopefully this model will work any types of service procurement including human resource hiring, maintenance service hiring, or product purchase where service is important.

Limitations

This model will work with service determination and service specification and strategy devising around those. Anything outside of that is out of scope of this model.

Besides, this model is tested in limited real life purchase decisions by procurement professionals. The result was more satisfactory than expected. But this model needs to be tested in an organized manner through survey and observation on application using statistical tools.

\section{Conclusion}

Service is integral to any product. More the product component gets lower, Service area gets higher [2]. Therefore specification of service is necessary. The service positioning model proposed in this article considers with most of the service components found in different literatures. Those components were classified and categorized together to identify desired service expectation. Hopefully, the derived model will work to specify the service desired by purchasers. With more studies this model will be better and serve its true purpose to make improved decisions in terms service procurement.

\section{References}

[1] Haksever, C., \& Render, B. (2013). Service management an integrated approach to supply chain management and operations.

[2] Zeithaml Valarie, Bitner Jo, Gremler Dwayne, (2006), Services Marketing, $4^{\text {th }}$ edition.

[3] Vargo, S. L and Lusch, R. L (2004). 'The four services marketing myths: Remnants from marketing model' Journal of service research (May): 324-35.

[4] Ellram, L. M. and A. Carr. "Strategic Purchasing: A History and Review of the Literature," International Journal of Purchasing and Materials Management, (30:2), Spring 1994, pp. 10-18.

[5] Carter, J. R. and R. Narasimhan. "Is Purchasing Really Strategic?" International Journal of Purchasing and Materials Management, (32:1), Winter 1996, pp. 20-28.

[6] Horizons Canada (2013). Significant Shifts in Key Economic Sectors. Retrieved April 10, 2017, from http://www.horizons.gc.ca/eng/content/significant-shifts-keyeconomic-sectors
[7] Statisticstimes. com (2017) Sector-wise contribution of GDP of India. (nd.). Retrieved April 10, 2017, from http://statisticstimes.com/economy/sectorwise-gdpcontribution-of-india.php

[8] Ovi, I. H. (2016). Export contribution to GDP declining. Retrieved April 10, 2017, from http://www.dhakatribune.com/bangladesh/2016/09/22/exportcontribution-gdp-declining/

[9] Kraljic, P. (1983). Purchasing Must Become Supply Management. Harvard Business review, (SEPTEMBER), 109-117.

[10] Stanley, L., \& Wisner, J. (2001). Service quality along the supply chain: implications for purchasing. Journal of Operations Management, 19(3), 287-306. doi:10.1016/s02726963(00)00052-8

[11] Cavinato, J. L., (1987). Purchasing performance: what makes the magic? Journal of Purchasing and Materials Management 23 (3), 10-16.

[12] Rossler, P. E., Hirsz, A. B., (1995). Purchasing's interaction with customers: the effects on customer satisfaction - a case study. International Journal of Purchasing and Materials Management 32 (1), 37-43.

[13] Young, J. A., Varble, D. L. (1997) 'Purchasing's performance as seen by its internal customers: a study in a service organization. International Journal of Purchasing and Materials Management', Journal of Marketing 58 (1), 132139. 33 (3), 36-41.

[14] Parasuraman, A., Zeithaml, V. A., Berry, L. L., (1985). A conceptual model of service quality and its implications for future research. Journal of Marketing 49 (4), 41-50.

[15] Parasuraman, A., Berry, L. L., Zethaml, V. A., (1991). Perceived service quality as a customer-based performance measure: an empirical examination of organizational barriers using an extended service quality model. Human Resource Management 30 (3), 335-364.

[16] Parasuraman, A., Zeithaml, V. A., Berry, L. L., (1985). A conceptual model of service quality and its implications for future research.

[17] Parasuraman, A., Zeithaml, V. A., Berry, L. L., (1988) SERVQUAL: a multiple-item scale for measuring consumer perceptions of service quality. Journal of Marketing 49, 4150 .

[18] Parasuraman, A., Zeithaml, V. A., Berry, L. L., (1994). Reassessment of expectations as a comparison standard in measuring service quality: implications for further research. Journal of Marketing, 58 (1), 111-124.

[19] Raedels, A., Buddress, L., ( 1993). A preliminary comparison of purchasing performance measures with customer and supplier performance measures. Developments in Purchasing and Materials Management, National Association of Purchasing Management, AZ, 58-63.

[20] Reynoso, J., Moore, B., (1995). Towards the measurement of internal service quality. International Journal of Service Industry Management 6 (3), 64-83.

[21] Zeithaml, V. A., Berry, L. L., Parasuraman, (1988). Communication and control processes in the delivery of service quality. Journal of Marketing 52 (4), 35-48. 
[22] Lewis, B. R., Gabrielsen, G. O. S., (1998). Intra-organisational aspects of service quality management: the employees' perspective. Services Industries Journal 18 (2), 64-89.

[23] Lewis, B. R., Koula, S., (1995). Service quality and internal marketing: an investigation in financial services. In: Proceedings of the British Academy of Management, 11-13 September, 385-397.

[24] Cronin Jr., J. J., Taylor, S. A., (1992). Measuring service quality: a reexamination and extension. Journal of Marketing $56(3), 55-68$.

[25] Cronin Jr., J. J., Taylor, S. A., (1994). SERVPERF versus SERVQUAL: reconciling performance-based and perceptionsminus-expectations measurement of service quality. Journal of Marketing 58 (1), 125-131.

[26] Teas, R. K., (1994). Expectations as a comparison standard in measuring service quality: an assessment of a reassessment. Journal of Marketing 58 (1), 132-139.

[27] Finn, D. W., Baker, J., Marshall, G. W., Anderson, R., (1996). Total quality management and internal customers: measuring internal service quality. Journal of Marketing Theory and Practice, 36-51.

[28] Kaplan, R. S., Norton, D. P., (1992). The balanced scorecard -measures that drive performance. Harvard Business Review $1 / 2,71-79$.

[29] Kaplan, R. S., Norton, D. P., (1993). Putting the balanced scorecard to work. Harvard Business Review 9/10, 134-147.

[30] Bowen, D., Schneider, B., (1988). Services marketing and management: implications for organizational behaviour. Research in Organizational Behaviour. JAI Press, Greenwich, CT.

[31] Flynn, B. B., Schroeder, R. G., Sakakibara, S., (1995). Determinants of quality performance in high- and low-quality plants. Quality Management Journal, 8-25.

[32] Berry, L. L., Parasuraman, A., Zeithaml, V. A., (1988). The service quality puzzle. Business Horizons 31(5), 35-43.

[33] Harvey, J., (1998). Service quality: a tutorial. Journal of Operations Management 16, 583-597.

[34] Peters, L. L., (1997). Adding value through strategic management of goods and services. Proceedings of the 1997 NAPM International Conference, 4-7 May.

[35] Lilliecreutz J. and Ydreskog L. (1999) Supplier classification as an enabler for a differentiated purchasing strategy, Global Purchasing \& Supply Chain Management. 66-74.

[36] Håkansson H. and Persson G (2006). Supplier segmentation when supplier relationships matter, NOFOMA conference proceedings. 63-75.

[37] Thompsen J. D. Organizations in Action, Mac Graw Hill, Inc., 1967.

[38] Gelderman (2000) Rethinking Kraljic: Towards a Purchasing Portfolio Model, Based on Mutual Buyer Supplier Dependence, Danish Purchasing \& Logistic Forum. October 2000. 10: Vol. 37. pp. 9-15.
[39] Van Stekelenborg R. H. A. and Kornelius L. (1994) A diversified approach towards purchasing and supply, IFIP Transactions. B, Applications in technology. 1994, 45-55.

[40] Olsen, R. F., \& Ellram, L. M. (1997). A portfolio approach to supplier relationships, Industrial Marketing Management, 26(2), 101-113.

[41] 41. Sage Publications, i., \& Lavrakas, P. J. (2008). Encyclopedia of Survey Research Methods. Thousand Oaks, Calif: SAGE Publications, Inc.

[42] 42. Allen, I. E., \& Seaman, C. A. (2007). Likert scales and data analyses. Quality Progress, 40(7), 64-65. Retrieved from https://login.proxy.hil.unb.ca/login?url=https://search-proquest com.proxy.hil.unb.ca/docview/214764202?accountid=14611

[43] Johnson, M. D., \& Nilsson, L. (2003). The importance of reliability and customization from goods to services. The Quality Management Journal, 10(1), 8-19. Retrieved from https://login.proxy.hil.unb.ca/login?url=https://searchproquestcom.proxy.hil.unb.ca/docview/213612474?accountid=14611

[44] Parasuraman, A., Zeithaml, V. A., Berry, L. L., (1988). Journal of Marketing 49, 41-50. SERVQUAL: a multiple-item scale for measuring consumer perceptions of service quality. Journal of Retailing 64, 12-37.

[45] ITC- International Trade Center (2002), Developing Supply Strategies, August 2002 Edition.

[46] Ostaeyen, J. V., Horenbeek, A. V., Pintelon, L., \& Duflou, J. R. (2013). A refined typology of product-service systems based on functional hierarchy modeling. Journal of Cleaner Production, 51, 261-276. doi:10.1016/j. jclepro.2013.01.036

[47] Caniëls, M. C., \& Gelderman, C. J. (2005). Purchasing strategies in the Kraljic matrix-A power and dependence perspective. Journal of Purchasing and Supply Management, 11(2-3), 141-155. doi:10.1016/j. pursup.2005.10.004.

[48] Dimitri Nicola (Ed), Gustavo Piga (Ed) And Giancarlo Spagnolo (Ed), Handbook of Procurement, 2006.

[49] Robert M. Monczka, Robert B. Handfield, Larry C. Giunipero, James L. Patterson, Purchasing And Supply Chain Management, $4^{\text {th }}$ Edition, 2009.

[50] Shahin, A. (2006), "SERVQUAL and model of service quality gaps: A framework for determining and prioritizing critical factors in delivering quality services", In: Service quality - An introduction, Partha Sarathy V. (ed), Andhra Pradesh: ICFAI University Press, pp. 117-131.

[51] Stanley, L. L., \& Wisner, J. D. (2002). The determinants of service quality: issues for purchasing. European Journal of Purchasing \& Supply Management, 8(2), 97-109. doi:10.1016/s0969-7012(01)00009-0

[52] Newstrom Jhon, Davis Keith, 2012, Consumer Behaviour, $12^{\text {th }}$ edition. 